\title{
Aesthetic Medicine-A Separate Field of Medicine, as a Combination of Many Medical Specialties
}

\author{
Anna Galęba ${ }^{1,2}$, Jerzy T. Marcinkowski1 ${ }^{*}$ \\ ${ }^{1}$ Department of Social Medicine, Poznan University of Medical Sciences, Poznan, Poland \\ ${ }^{2}$ Private Practice of Aesthetic Medicine and Anti-Aging, Warszawa and Poznan, Poland \\ Email: *itmarcin@gmail.com
}

Received 11 February 2015; accepted 22 February 2015; published 27 February 2015

Copyright (C) 2015 by authors and Scientific Research Publishing Inc.

This work is licensed under the Creative Commons Attribution International License (CC BY). http://creativecommons.org/licenses/by/4.0/

c) (i) Open Access

\begin{abstract}
Aesthetic medicine is not a new area of medicine. It has been on the world's market for several dozen years. Aesthetic and anti-aging medicine is a separate field of medicine combined with other areas such as: neurology, plastic surgery, cosmetic surgery, general surgery, orthopaedics, psychology, psychiatry, dermatology, gynaecology, andrology, endocrinology and so on. Aesthetic medicine is an area of medicine, dealing with human's health in terms of: external appearance, image, aesthetics, well-being, visible skin changes and discomfort in the quality of life felt by a patient. The purpose of aesthetic medicine is to achieve patients' satisfaction, as to their requirements related to the appearance, elimination of the complexes and the restoration of self-esteem. The following work shows, based on the overall impact of aesthetic medicine on the lives of patients and on the basis of the characteristics of some basic treatments in aesthetic medicine (fillers, botulinum toxin type $A$, intralipotherapy, needle mesotherapy, chemical peels), how this area of medicine is linked with other specialties and why it should be treated as a separate field of medicine.
\end{abstract}

\section{Keywords}

Aesthetic Medicine, Cosmetic Medicine, Multi-Specialties, Aesthetic Treatments

\section{Introduction}

The need of being beautiful and attractive, have existed in all human civilizations, today however, it is more

${ }^{*}$ Corresponding author. 
pronounced than in any other time. It is rare that our body and our appearance do not concern us. The ideal beautiful body does not exist. Beauty ideal however has existed forever. A beautiful body is not only its physical attractiveness, it is above all maintaining a harmony between the soul and the body, which is reflected on the face, in the way one move, talk, expresses oneself, in ones charm, behaviour, education and so on. It combines the whole physical, mental and psychological habitus of a person (lat. habitus-character, features) [1].

Cosmetic doctors (aesthetic medicine doctors) take care of our appearance and indirectly of our well-being. Aesthetic medicine is not a new area of medicine. On the world market it has been for several dozen years. The creator of aesthetic medicine was a French physician, endocrinologist Jean Jacques Legrand. On his initiative the society of aesthetic medicine was founded in Paris in 1973. Two years later, the surgeon Carlo Alberto Bartoletti founded such association in Rome. Soon other associations were formed, respectively in Belgium and in Spain. In 1978 all those four countries formed an International Association of aesthetic medicine, based in Paris. Over time, there were created other world organizations in the US and in Asia [2].

Aesthetic and anti-aging medicine is a separate field of medicine combined with other areas such as: neurology, plastic surgery, cosmetic surgery, general surgery, orthopaedics, psychology, psychiatry, dermatology, gynaecology, andrology, endocrinology and so on. Aesthetic medicine is an area of medicine, dealing with human's health in terms of: external appearance, image, aesthetics, well-being, visible skin changes and discomfort in the quality of life felt by a patient. Should no longer be treated with neglect, "as a vain part of proper medicine", because of the huge impact of its effects on the mental health of patients [1]. It should be strived to create a separate specialty in this field.

The following work shows, based on the overall impact of aesthetic medicine on the lives of patients and on the basis of the characteristics of some basic treatments in aesthetic medicine (fillers, botulinum toxin type A, intralipotherapy, needle mesotherapy, chemical peels), how this area of medicine is linked with other specialties and why it should be treated as a separate field of medicine.

\section{Aesthetic Medicine as a Combination of Numerous Medical Specialties}

Cosmetic doctor through aesthetic and anti-aging medicine treatments, lead to improvement in the appearance of their patients, who as a result, often regain the psychological balance, obtain more confidence, thanks to which can achieve many dreams related to their personal or professional life [1]. The purpose of aesthetic medicine is to achieve patients' satisfaction, as to their requirements related to the appearance, elimination of the complexes and the restoration of self-esteem. In order to preserve the beauty one needs to take care of it from the earliest years to the old age. Some patients want to delay the external signs of the aging process or to improve their external appearance due to the work they carry, others as a result of internal stress and mental reluctance to contact with people, complexes, psychosis, neuroses and other mental disorders. Yet another group, are patients after accidents, as a result of which have suffered permanent injuries, and those who came to the world with congenital defects [1].

Cosmetic doctor not only changes the appearance of the patient in the physical way but also influences his psychics and wellbeing, thanks to which such patient can easier accomplish his desires related to his life. Aesthetic medicine is a branch of medicine that deals with the construction and reconstruction of human psychophysical balance, so it is related to psychology and even to psychiatry. It is primarily addressed to those patients who find it difficult to accept their own aesthetic defects. This is the medicine focused on the quality of life, and health is treated here as an expression of good mental and physical condition. It is a branch of medicine that mainly has a preventive character, and only then reconstructive, therefore corrective. In the preventive phase of cosmetic doctor teach patients how to get to know and accept the physical structures, that have been inherited, how to take care of them and how to handle them in accordance with the rules of hygiene of life related to nutrition, mental and physical exercise, as well as cosmetic hygiene. The corrective phase provides for the application of only officially recognized treatments and procedures such as medical, surgical, physiotherapeutic, cosmetic and spa. Cosmetic doctor is a person who not only physically changes the appearance of the patient but also affects his mental state and well-being, so it is easier for such patient to accomplish dreams related to his life [1] [3].

There are several factors that influence aging of our body as a whole, those are internal and external factors (proper aging, improper aging) [1] [4]. Telomeres play a key role in aging, at the cellular level, their length shortens with age of the body. As a result of shortening of the telomeres, there occur cell aging and tissue deterioration. Telomeres protect DNA, in the chromosomes' ends, from shortening during the divisions. This phenomenon prevents a systematic loss of valuable genetic material [5]. The speed of aging process and the age at 
which the first symptoms of old age occur is conditioned upon genes (proper ageing, over which we have no influence). The rate of aging is also dependent on many external factors (improper aging, on which we have impact through appropriate prevention) such as: the nature of the work we do, climatic conditions as well as the way of onto genic exploitation, however the greatest influence among exogenous factors is attributed to: exposure to UV rays (tanning, solarium), smoking, bad nutrition and addictive substances (e.g. alcohol, excessive amounts of coffee). Hormonal disorders (both excess and deficiency) are also responsible for the cause of poor appearance (of skin, hair) as well as disorders in body weight. During menopause, additionally, there is a decrease in the secretion of estrogen (17-beta-estradiol, to be exact). Estrogen deficiency contributes to reduction in the amount of collagen (decrease in the thickness of the skin layer, loss of elasticity and tension), decrease in the activity of the sebaceous glands and sweat glands (dry, rough skin), as well as a decrease in the level of hyaluronic acid, elastin fibers, capillaries and loss of subcutaneous tissue [1] [4]. From the perspective, aesthetic medicine is the closest associated with endocrinology and gynecology.

Local excess of adipose tissue (e.g. in the area of the abdomen, outer side of the thigh, chin) is very difficult to get rid of through adequate diet and physical exercise. For that reason some doctors use invasive methods to remove excess of the body fat-liposuction, which is a surgical procedure and is associated with numerous side effects and less invasive methods (non-surgical) such as intralipotherapy. It is a local removal of excess fat, that is based on the destruction of dual protein-lipid membrane complexes, that surround the adipose cell (by using sodium deoxycholate) [6]-[8], or by the destruction of fat deposits in fat cell without destroying the double membranes (using a phosphatidylcholine) [9]-[12]. These treatments are performed by entering a long, thin needle (usually $7-10 \mathrm{~cm}$ ) deep into body fat. These treatments are an alternative to liposuction and are closely related to the cosmetic surgery.

Fillers are treatments involving the subcutaneous or deep to the bone introduction of substances that play a filling role. Hyaluronic acid is now one of the most common constituents of fillers. It is a natural compound that occurs in the skin, the eyeball and the inter-joint space. Another, equally popular "filler" is own adipose tissue, which is introduced together with platelet-rich plasma in the particular place. Fillers are most commonly used within the face or hands, but more and more popular are aesthetic treatments of filling in the genital area (both women and men-penis, labia majora and minora, vagina, pubis). Patients go to doctors dealing with rejuvenating of female genitals not only for aesthetic reasons but also functional [13]. It is important here (if must, since the aesthetic medicine is a separate field of medicine) to find connection of filler treatments with general surgery, cosmetic surgery, and rology and gynecology.

Treatment with botulinum toxin type A (TXB-A) causes muscle paralysis, by blocking secretion of acetylcholine $(\mathrm{ACh})$ in the plane of nervous-muscular connections of skeletal muscle, therefore inhibiting the transmission of nerve impulses through the synaptic connections to the kinesthetic part of the plate. The nervous-muscular transmission gets interrupted and there is a blockage of the muscle, however over time the target muscle is reversibly paralyzed. These treatments, by inhibiting secretion of ACh, also lead to a blockage of the sympathetic innervation of sweat glands-causing inhibition of excessive sweating. TXB-A blocks the release of ACh from presynaptic nerve endings, because it contains tin endopeptidase, which is responsible for the distribution of SNAP-25 protein, necessary to the process of exocytosis of the synaptic vesicles containing ACh (from the presynaptic part to the postsynaptic part) [14]. In this situation, these treatments are the closest combined with neurology because of the inhibition of secretion of Ach from the presynaptic nerve endings, or orthopedics, because the TXB-A is introduced deep into the muscles in order to eliminate wrinkles, bruxism, gummy smile, platysmal neck bands, downturn of corners of the mouth, etc.

Chemical peels are treatments that led to exfoliation of stratum corneum or dermis, depending on the type of the substance and the intensity of the treatment, which is customized to the condition in which the patient's skin is in [15]. They are the closest related to dermatology. Chemical peels in terms of the depth of their actions can be divided into superficial (very mild and mild), medium-deep and deep [1] [15]. These treatments are carried out by cosmetologists (very superficial peels), cosmetic doctors and dermatologists (superficial peels and medium-deep) and plastic or cosmetic surgeons (deep peels-Baker-Gordon's phenol peel) [1]. Superficial peeling, very mild works only within the epidermis (in a few of its layers - from the stratum corneum layer to the stratum spinosum), is safe and can therefore be carried out by an appropriately educated and trained cosmetician. Mild peels and medium-deep work in the deeper layers of the skin (cover the entire epidermis, dermal papilla up to the reticular layer of the skin). It shall be carried out by the doctor, because it is important to recognize the appropriate diagnosis and appropriate treatment and to have expertise to cope with the possible complications. 
Baker-Gordon Phenol Peeling (acts on the central part of the reticular layer of the skin) due to the systemic properties of phenol (arrhythmias such as: tachycardia, atrial fibrillation, ventricular premature beats) in the case of applications on the larger areas of the skin, such treatment is performed in the operating room, often under anesthesia, in the presence of an anesthesiologist.

Mesotherapy-the first treatment was conducted in 1952, in France by M. Pistor (the patient suffered from mishearing), who noted that applying a topical medication in the surroundings of the sick place works more efficiently, because the drug avoids, among others: the digestive system, the liver. The first treatments were carried out in order to treat deafness, migraines, neurological disorders, varicose veins, and respiratory diseases, but with time, since the 1970's needle mesotherapy began to be used also for aesthetic purposes (e.g.: skin rejuvenation, treatments for hair loss and alopecia, treatments for skin stretch mark and cellulite). These treatments can be used in skin biorevitalisation using two mechanisms in order to rejuvenate it, the first one is the substance or medication injected directly into the skin, the second is the focal effect of wound healing after numerous injections. Mesotherapy for years has been used not only in the aesthetic medicine and dermatology but also in sports medicine (e.g. in the treatment of damaged tendons and ligaments), in surgery (e.g. to accelerate the wound healing process after surgery, in the treatment of ulcers and burns), in internal medicine (e.g. in the treatment of chronic inflammatory diseases, chronic pain syndromes, in the treatment of obesity) and even in psychiatry (in the treatment of anxiety states and depression) [15] [16].

\section{The Effect of Attractiveness on Our Lives}

Galeba A. [1], Glen T. Porter and Francis B. Quinn [17], Clifford and Walster [18], Riniolo et al. [19] showed in his studies that beautiful people are higher rated and get lower sentences in comparison to less prettier, it's easier for them to find life partners, work, are more often considered to be pleasant people, are served faster, they are sooner helped when they need it and they are even sooner forgiven. It has been proven that physically attractive candidates for work, with proper education and qualifications as good as the less attractive people, have higher chances for being employed [20]. Employees with a more attractive beauty earn about $10 \%-15 \%$ more in relation to less attractive ones [21]. A study carried out by psychologists, has shown that people who consider themselves attractive, higher rate their mental health and are more extravertic [22].

We live in times where appearance plays great importance in society. Scientists who deal with this subject have presented a lot of evidences that show that admiration for the beauty of the body and the ability to recognize it is inherited after ancestors, and the ability to recognize an attractive, beautiful face is possible as fast as for 2 - 6 months infants. It has been proven that one year old children play with dolls that have beautiful faces twice as long as with the ones with unattractive faces [23]. So the ability to tell the beauty from ugliness is already passed to us in the genes. It's difficult for us to admit that our assessment of the character traits and behaviors of other persons is affected by their appearance [1].

\section{Conclusion}

Aesthetic and anti-aging medicine (cosmetic medicine) is a young field of medicine compared to other areas. It is a combination of numerous medical specialties, and should get to the specialization statue, a separate field in medicine. Perhaps a lot of people consider it "as the vain" part of the medicine, however, one should not agree with this, seeing how much it affects the psyche, the satisfaction of patients and their lives. How it improves their lives. It makes us regain the confidence and we begin to pursue our dreams related to personal and professional life. Aesthetic and anti-aging medicine its influence on improvement of our life cannot be underestimated. It is a very important field of medicine and should become a separate medical specialization.

\section{References}

[1] Galęba, A. (2011) Evaluation of the Quality of Life of Patients before and after the Selected Treatments in Aesthetic Medicine. Doctoral Thesis, Poznan University of Medical Sciences, Poznan.

[2] Dylewska-Grzelakowska, J. (1999) Kosmetyka Stosowana [Cosmetology Applied]. WSiP, Warsaw.

[3] Galęba, A. and Bajurna, B. (2010) Influence of Aestheticmedicine to Function in Society. In: Głowacka, M.D. and Galicki, J., Eds., Efficient Management of Healthcarefacility, Polskie Towarzystwo Nauk o Zdrowiu, Poznan, 257-268.

[4] Galęba, A., Bajurna, B. and Shankar, S. (2014) Premature Skin Aging-A Process That Can Be Slowed Down by 
Appropriate Prevention. Hygeia Public Health, 49, 708-711.

[5] (2011) The Nobel Prize in Physiology or Medicine 2009. Nobelprize.org. http://nobelprize.org/nobel_prizes/medicine/laureates/2009/

[6] Rotunda, A.M., Suzuki, H., Moy, R.L. and Kolodney, M.S. (2004) Detergent Effects of Sodium Deoxycholate Are a Major Feature of an Injectable Phosphatidylcholine Formulation Used for Localized Fat Dissolution. Dermatologic Surgery, 30, 1001-1008.

[7] Rotunda, A.M., Ablon, G. and Kolodney, M.S. (2005) Lipomas Treated with Subcutaneous Deoxycholate Injections. Journal of the American Academy of Dermatology, 53, 973-978. http://dx.doi.org/10.1016/j.jaad.2005.07.068

[8] Palumbo, P., Melchiorre, E., La Torre, C., Miconi, G., Cinque, B., Marchesani, G., Zoccali, G., Maione, M., Macchiarelli, G., Vitale, A.R., Leocata, P., Cifone, M.G. and Giuliani, M. (2010) Effects of Phosphatidylcholine and Sodium Deoxycholate on Human Primary Adipocytes and Fresh Human Adipose Tissue. International Journal of Immunopathology and Pharmacology, 23, 481-489.

[9] Hasengschwandtner, F. (2005) Phosphatidylcholine Treatment to Induce Lipolysis. Journal of Cosmetic Dermatology, 4, 308-313. http://dx.doi.org/10.1111/j.1473-2165.2005.00211.x

[10] Salles, A.G., Valler, C.S. and Ferreira, M.C. (2006) Histologic Response to Injected Phosphatidylcholine in Fat Tissue: Experimental Study in a New Rabbit Model. Aesthetic Plastic Surgery, 30, 479-485. http://dx.doi.org/10.1007/s00266-005-0210-1

[11] Schuller-Petrovic, S., Wölkart, G., Höfler, G., Neuhold, N., Freisinger, F. and Brunner, F. (2008) Tissue-Toxic Effects of Phosphatidylcholine/Deoxycholate after Subcutaneous Injection for Fat Dissolution in Rats and a Human Volunteer. Dermatologic Surgery, 34, 529-543.

[12] Hoffmann, K. (2010) Injectionlipolysis. Der Hautarzt, 61, 847-855. http://dx.doi.org/10.1007/s00105-010-1984-x

[13] Ishii, C.H. (2013) Book Review: Be Your Best: A Comprehensive Guide to Aesthetic Plastic Surgery, Written by the Experts. Aesthetic Surgery Journal, 33, NP5-6. http://dx.doi.org/10.1177/1090820X12467791

[14] Huang, W., Foster, J.A. and Rogachefsky, A.S. (2000) Pharmacology of Botulinum Toxin. Journal of the American Academy of Dermatology, 43, 249-259. http://dx.doi.org/10.1067/mjd.2000.105567

[15] Adamski, Z. and Kaszuba, A. (2008) Dermatologia dla kosmetologów [Dermatology for Cosmetologists]. Wydawnictwo Naukowe Uniwersytetu Medycznego w Poznaniu, Poznan, 265-274.

[16] Galęba, A. (2010) Mezoterapia_Jako jedna z metod biorewitalizacji skóry [Mesotherapy—As a Method of Skin Biorevitalization]. Dermatologia Estetyczna, 1, 34-40.

[17] Glen, T., Porter, M.D., Francis, B. and Quinn Jr., M.D. (2004) Preoperative Evaluation of the Aesthetic Patient. http://www2.utmb.edu/otoref/Grnds/Preop-eval-2004-0421/Preop-eval-slides-2004-0421.pdf

[18] Clifford, M. and Walster, E. (1973) The Effect of Physical Attractiveness on Teacher Expectations. Sociology of Education, 46, 248-258.

[19] Riniolo, T.C., Johnson, T.R. and Misso, J.A. (2006) Hot or Not: Do Professors Perceived as Physically Attractive Receive Higher Student Evaluations. The Journal of General Psychology, 133, 19-35. http://dx.doi.org/10.3200/GENP.133.1.19-35

[20] Marlowe, C.M., Schneider, S.L. and Nielson, C.E. (1996) Gender and Attractiveness Biases in Hiring Decisions: Are More Experienced Managers Less Biased? Journal of Applied Psychology, 8, 11-21. http://dx.doi.org/10.1037/0021-9010.81.1.11

[21] Hamermes, D.S. and Biddle, J.E. (1994) Beauty and the Labor Market. The American Economic Review, 84, 11741194.

[22] Feingold, A. (1992) Good-Looking People Are Not What We Think. Psychological Bulletin, 111, 304-341.

[23] Langlois, J.H., Roggman, L.A. and Rieser-Danner, L.A. (1990) Infants' Differential Social Responses to Attractive and Unattractivefaces. Developmental Psychology, 26, 153-159. http://dx.doi.org/10.1037/0012-1649.26.1.153 